\title{
Numerical Investigation into the Effect of Fins on Fluid Natural Convection in Coaxial Annuli
}

\author{
Mohammad Reza Tavakoli, Mahsa Farzaneh, Arash Shadlaghani \\ Department of Mechanical Engineering, Isfahan University of Technology \\ Isfahan, 8415683111, Iran \\ mrtavak@cc.iut.ac.ir; mahsa.farzaneh@me.iut.ac.ir, a.shadlaghani@me.iut.ac.ir
}

\begin{abstract}
This paper attempted to numerically examine the involvement of serrated fins on natural convection heat transfer between coaxial cylinders. The outer channel of annular cylinders was circular, while the inner channels involved three cross-sections including circular, square and triangular. As two geometric constraints, the area of annular cylinders and the diameter of outer channel were assumed to be identical in each scenario explored in this study. The fins had equal areas placed on the inner surface, so as to compare their effects on thermal properties of annular cylinders under constant temperature boundary within the range of Rayleigh numbers from $10^{5}$ to $10^{8}$. The results indicated that higher a Rayleigh number is directly correlated with higher convection heat transfer coefficient of surfaces. However, the inclusion of fins reduced the rate near the fins, thus mitigating the heat transfer coefficient of inner channel. This trend intensified at higher Rayleigh numbers. Therefore, the involvement of fins at lower Rayleigh numbers brings about greater efficiency in heat transfer. The comparison of fins in terms of efficiency revealed that maximum heat is transferred when the fins have been mounted on a circular channel.
\end{abstract}

Keywords: Coaxial Annular Cylinders, Natural Convection, Fins, Numerical Simulation

\section{Introduction}

As one of the mechanisms of fluid heat transfer, natural convection occurs when a body force is applied to a fluid due to differences in density. It should be noted that the density difference is caused by temperature fluctuation, while the body force is practically the same as buoyancy force. Although the heat transfer rate of natural convection is lower than that for forced convection, it plays a key role in the design and operation of thermal and fluid components including transmission lines and pipes, electronic equipment and heat exchangers.

One of the major factors contributing to heat transfer is natural fluid flow between coaxial cylinders, which are widely applied in solar collectors and other energy storage systems. In this regard, there have been a great deal of numerical and experimental research conducted mostly on flow between cylinders. Ken and Goldstein [1-2] carried out one of the most important studies on natural convection heat transfer between coaxial annular cylinders, which has been frequently cited by numerous subsequent relevant papers. Exploring the effect of eccentricity of inner cylinder and Rayleigh number on the heat transfer of horizontal cylinders, they found that eccentricity alters the Nusselt number on cylinder surfaces, while slightly altering the overall heat transfer of annular cylinders. Relying on numerical and theoretical methods, they also analyzed the temperature distribution, heat transfer rate and coefficient. Several other studies have so far been published in this regard. For instance, this section provides a better insight into relevant literature by reviewing previous works specifically focusing on inner flow of two-dimensional coaxial annular cylinders, where natural convection heat transfer plays a major role. In a review article, Davoud et al. [3] elaborated on several experimental and numerical studies on heat transfer of free and combined flow convection between horizontal, inclined and vertical coaxial annular cylinders. They also provided a list of most important studies separately by methodologies. Sucker et al. [4] explored the natural convection between two horizontal coaxial ovals through experimental and numerical methods. Their results revealed that an increase in hydraulic diameter initially leads to lower heat transfer, followed by an upward trend. In their study, Seidi et al. [5] simulated natural convection heat transfer for a nanofluid between cylinders. In fact, the inner wall was under constant heat flux while the outer wall was under constant temperature. The results indicated that Nusselt number increases at higher Rayleigh numbers and higher aspect ratios. Habibi et al. [6] studied the natural convection of copper nanofluids flowing into an eccentric cylinder under constant boundary temperature through numerical methods. They explored how 
the average Nusselt number, flow and temperature lines were affected by several parameters including eccentricity ratio, different radii, Rayleigh number, Prandtl number and concentration of nanoparticles. Padilla et al. [7] simulated the natural convection between horizontal annular cylinders at small and medium Rayleigh numbers. They then compared the results against experimental results. Zhang et al. [8] numerically simulated the natural and unsteady fluid convection between annular cylinders. In this study, the inner cylinder was under time-varying sinusoidal heat flux, while the outer cylinder was under constant temperature. The examination of parameters such as the radius of inner cylinder, amplitude and frequency of flux fluctuations indicated that temperature fluctuations altered the pattern of fluid flow and temperature. Limitations such as dimensions of annular cylinders prompted researchers to improve the heat transfer rate of fluids inside annular cylinders. Fins are mainly used to increase heat transfer rate. In case of annular cylinders, fins specifically enhance roughness and contact area, while altering the flow and temperature patterns. This subject has been covered by numerous studies including that of Patankar and Chaee [9]. They numerically analyzed the fluid flow between horizontal coaxial annular cylinders, where the inner cylinder contains six fins. The results showed that the orientation of fins did not significantly affect the overall heat transfer coefficient. It was only effective in the local Nusselt number and flow and temperature pattern of the inner cylinder. Similarly, Arbaban and Salimpour [10] numerically simulated and analyzed the heat transfer of natural and slow convection for nanofluids between finned annular cylinders. The results showed that copper-water nanofluids involved greater heat than aluminum oxide-water and titanium oxide-water nanofluids.

In the current study, the effect of serrated fins with rectangular cross-section was numerically simulated when the outer channel of the annular cylinder is circular and inner channel assumes different geometries including circle, square and triangle with identical areas. Figure (1) illustrates the geometries studied in this paper. This study intended to numerically compare the presence and absence of serrated fins on the heat transfer rate of fluids and the flow pattern.
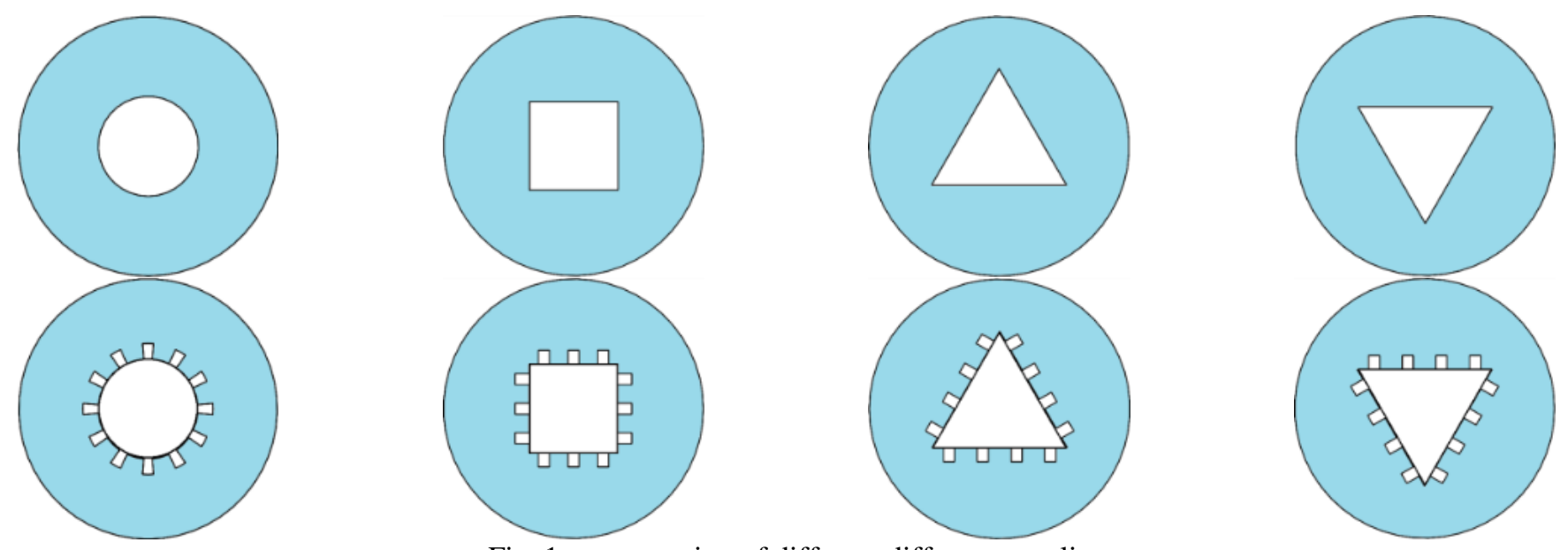

Fig. 1: cross section of different different annuli.

\section{Geometry of Solution and Governing Equations}

The geometry in this study involved coaxial annular cylinders with different inner channels as shown in Figure (1). The boundary conditions imposed and geometric constraints applied in this study (i.e. cross-sectional area of fluid and diameter of outer channel) were assumed to be identical in all geometries, thereby to specify the dimensions of inner channel. With fixed areas, the fins were mounted on the outer surface of the inner channel. The temperature difference between the inner and outer surfaces allowed natural convection to flow in the space between channel surfaces. The dimensionless quantities included Grashof number (Gr), Prandtl number (Pr) and Rayleigh number (Ra), specified through the following equations:

$$
\begin{gathered}
p r=\frac{v}{\alpha} \\
\mathrm{d}_{\mathrm{h}}=4 \mathrm{~A} / \mathrm{p}
\end{gathered}
$$




$$
\begin{aligned}
& G r=\frac{g \beta \Delta T d_{h}^{3}}{v^{2}} \\
& R a=\frac{g \beta \Delta T d_{h}^{3}}{v \alpha}
\end{aligned}
$$

Where, $d_{\mathrm{h}}$ and $\Delta \mathrm{T}$ represent hydraulic radius and their surface temperature difference, respectively. Moreover, $\beta$ is volumetric expansion coefficient used in Boussinesq approximation for the relationship between density and temperature variations. Rayleigh number is a measure for transition of natural convection. One noteworthy point is about how to calculate the heat transfer coefficient. It is determined based on bulk temperature $\left(T_{\text {bulk }}\right)$ the between the annular cylinders. In the geometries of this study, the heat transfer coefficient was calculated as the average temperature of surfaces. After calculating the convection coefficient, the Nusselt number was calculated for inner and outer surfaces through Equation (5) as follows:

$$
N u_{o}=\frac{h_{o} d_{h}}{k_{f}}, N u_{i}=\frac{h_{i} d_{h}}{k_{f}}
$$

Where, $h_{o}$ is the outer surface convection coefficient, $\mathrm{h}_{\mathrm{i}}$ is the inner surface convection coefficient, and $k_{f}$ is the fluid's coefficient of thermal conductivity.

\section{Numerical Analysis}

The governing equations included the equations of continuity, momentum and energy in the permanent and slow fluid flow under a 2D cylindrical coordinates as follows:

$$
\begin{gathered}
\frac{1}{r} \frac{\partial r V_{r}}{\partial r}+\frac{\partial V_{\theta}}{r \partial \theta}=0 \\
\rho\left(V_{r} \frac{\partial V_{r}}{\partial r}+\frac{V_{\theta}}{r} \frac{\partial V_{r}}{\partial \theta}-\frac{V_{\theta}}{r^{2}}\right)=-\frac{\partial P}{\partial r}+\mu\left(\frac{\partial^{2} V_{r}}{\partial r^{2}}+\frac{V_{\theta}}{r} \frac{\partial V_{r}}{\partial \theta}+\frac{1}{r^{2}} \frac{\partial^{2} V_{r}}{\partial \theta^{2}}-\frac{2}{r^{2}} \frac{\partial V_{\theta}}{\partial \theta}-\frac{V_{r}}{r^{2}}\right)+\rho g \beta \Delta T \cos \theta \\
\rho\left(V_{r} \frac{\partial V_{\theta}}{\partial \theta}+\frac{V_{\theta}}{r} \frac{\partial V_{\theta}}{\partial \theta}+\frac{V_{\theta} V_{r}}{r}\right)=-\frac{1}{r} \frac{\partial P}{\partial \theta}+\mu\left(\frac{\partial^{2} V_{\theta}}{\partial r^{2}}+\frac{1}{r} \frac{\partial V_{\theta}}{\partial r}+\frac{1}{r^{2}} \frac{\partial^{2} V_{\theta}}{\partial \theta^{2}}-\frac{2}{r^{2}} \frac{\partial V_{r}}{\partial \theta}-\frac{V_{\theta}}{r^{2}}\right)+\rho g \beta \Delta T \sin \theta \\
V_{r} \frac{\partial T}{\partial r}+\frac{V_{\theta}}{r} \frac{\partial T}{\partial \theta}=-\mu\left(\frac{\partial^{2} T}{\partial r^{2}}+\frac{1}{r} \frac{\partial V_{\theta}}{\partial \theta}+\frac{1}{r^{2}} \frac{\partial^{2} T}{\partial \theta^{2}}\right)
\end{gathered}
$$

Moreover, viscous dissipation was discarded due to slow natural convection rates. The insertion of a buoyant term in the equation couples all equations together. The natural convection is permanent and slow caused by temperature difference between annular surfaces. In the boundary conditions, the inner wall and outer wall were kept at temperatures of $373 \mathrm{~K}$ and $327 \mathrm{~K}$, respectively. The Prandtl number was calculated to be 2.29 for water based on fluid's bulk temperature.

For all annular cylinders, the outer channel diameter was $9.25 \mathrm{~mm}$ and inner channel diameter was $3.56 \mathrm{~mm}$. The thickness and length of fins were $0.4 \mathrm{~mm}$ and $0.5 \mathrm{~mm}$, respectively. The Navier-Stokes equations for outer twodimensional annular cylinders were numerically solved through ANSYS CFX. The transition term of the momentum equation was solved by a high resolution algorithm. The equations were solved until the resolution reached less than $10^{-5}$ for momentum and continuity equations and less than $10^{-6}$ for the energy equation. 
The uniform appearance will assist the reader to read paper of the proceedings. It is therefore suggested to authors to use the example of this file to construct their papers. This particular example uses an American letter format with $25 \mathrm{~mm}$ margins left, right, top and bottom.

\subsection{Grid Study}

One of the most important steps in numerical simulations is to check the independence of results from the number and type of grid. Structured mesh was employed for the domain of solutions (Fig. 2).

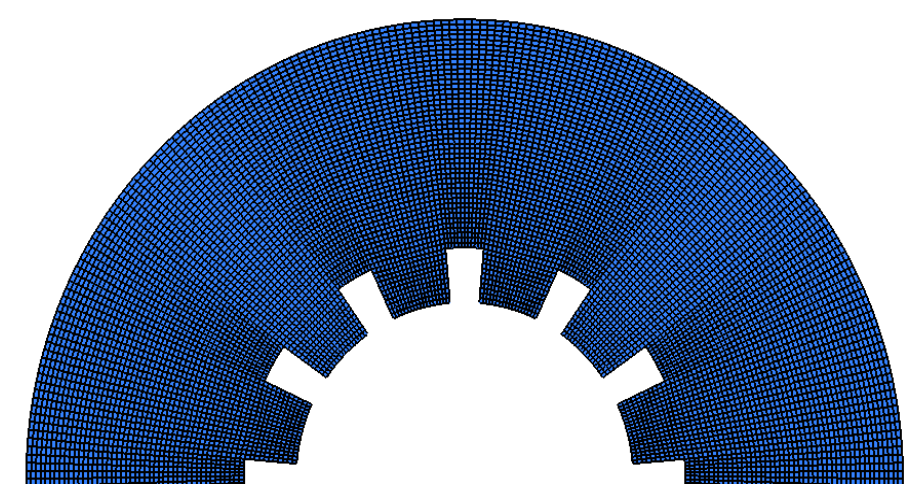

Fig. 2: Structured meshing inside the fluid domain.

The independence of results from number mesh number and type was evaluated by increasing the number of mesh until the annular velocity profiles overlapped. Table 1 shows the number of grids used for grid study.

Table 1: Number of elements used for grid study.

\begin{tabular}{|l|l|l|l|l|}
\hline & Coarse & Medium & Fine & Refine \\
\hline No. & 4560 & 5620 & 6706 & 7868 \\
\hline
\end{tabular}

Figure (3) shows the velocity variations for different grid types. As can be seen, the velocity profiles progressively match each other by increasing the number of mesh. According to the fluid's velocity profile, the values of velocity are greater in the upper part of annular cylinder than the lower part. This occurs because the upper part of the annular cylinder, i.e. warmer surface, lies lower than the cooler surface ( $\mathrm{Ti}>\mathrm{To}$ ), which intensifies the fluid natural convection. Conversely, there are nearly stable conditions for the fluid at the lower part fluid, not to mention that the fluid velocity is relatively smaller. Figure (3) illustrates a sample of mesh using in this study.

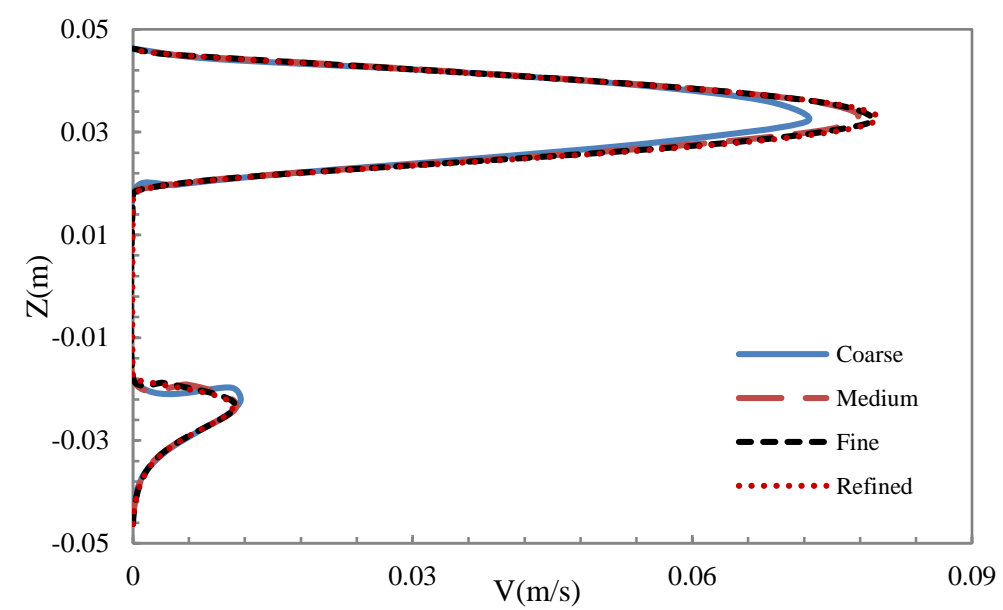

Fig. 3: Grid study for cylindrical annulus. 


\subsection{Validation}

Table 2 displays the properties of water at bulk temperature for fluid water in all simulations.

Table 2: Properties of water.

\begin{tabular}{|c|c|c|c|c|c|}
\hline$\rho$ & $\mu$ & $K$ & $C_{p}$ & $\operatorname{Pr}$ & $\operatorname{Ra}$ \\
\hline $974\left(\mathrm{~kg} / \mathrm{m}^{3}\right)$ & $365^{*} 10^{-6}(\mathrm{~N} . \mathrm{S} / \mathrm{m})$ & $0.665(\mathrm{w} / \mathrm{m} . \mathrm{K})$ & $4195(\mathrm{~J} / \mathrm{kg} . \mathrm{K})$ & 2.29 & $10^{5}, 10^{6}, 10^{7}, 10^{8}$ \\
\hline
\end{tabular}

The equivalent conductivity was employed to ensure the numerical method. Thermal conductivity $\left(\mathrm{K}_{\mathrm{eq}}\right)$ represents the ratio of natural convection heat transfer to net conductivity as a measure to compare the two types of heat transfers. Thermal conductivity is formulated for inner and outer channels as follows: [9]

$$
K_{e q}=\frac{\operatorname{hdLn}\left(\frac{d_{i}}{d_{o}}\right)}{2 k_{f}}
$$

Where, $h$ is the surface convection coefficient, $\mathrm{d}_{\mathrm{i}}$ is the inner diameter, and $\mathrm{k}_{\mathrm{f}}$ is the fluid's conductivity coefficient. The numerical results of simulation for the fin-less annular cylinder at Rayleigh number of 104 were compared under identical conditions against the experimental results [2]. Figure (4) indicates good consistency between the experimental and numerical results.

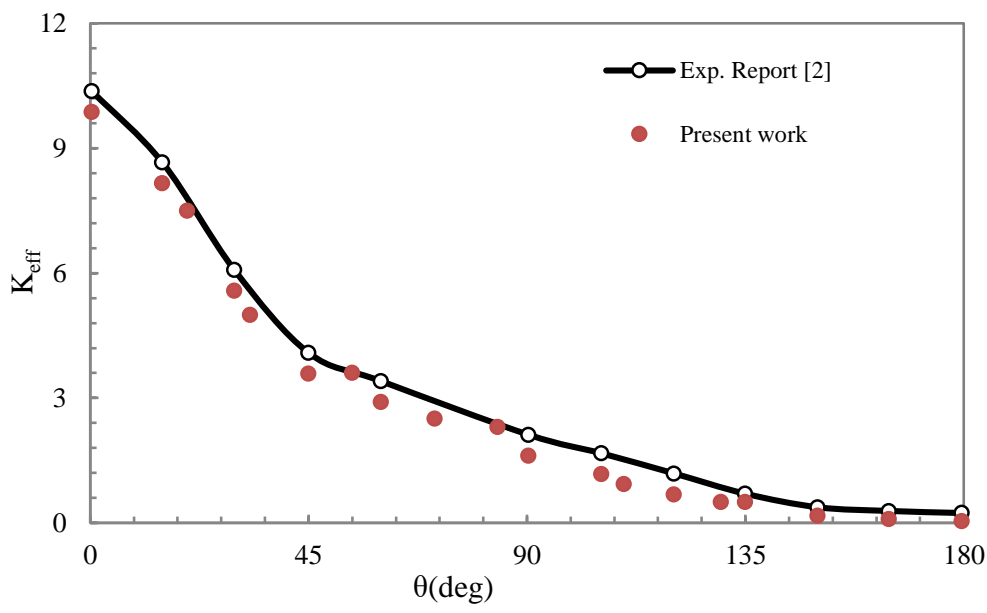

Fig. 4: Comparison of results with experimental report.

\section{Results and Discussion}

\subsection{Temperature Distribution and Thermal Performance}

In fact, the share of convection overruns conduction. It should be noted that conduction is the dominant mechanism of heat transfer at low Rayleigh numbers due to insignificant fluid conductivity. This highlights the accuracy of the contour obtained for fluid temperature variations. The fluid temperature variations tend to be more extreme in the upper part of annular cylinders because the warm surface lies below the cool surface. As the Rayleigh number increases, the temperature curve on the top of an annular cylinder indicates more intense variations, because thermal instability of the flow due to temperature difference initiates sooner on the upper part of the annular cylinder than other areas. It can be deduced from results in Table (2) that involvement of fins improves the Nusselt number of the outer surface. This can be associated more with the larger share of the inner domestic channel's contact area despite its reduced convection coefficient owing to involvement of fins. With the constant overall heat transfer of surfaces (there is no energy generation or dissipation), the convection coefficient of outer surface increases given the fixed area according to the law of energy balance. 
Table 3: Comparison of Nusselt numbers of internal and external surface with and without fins.

\begin{tabular}{|l|c|c|c|c|c|c|c|c|}
\hline & \multicolumn{2}{|c|}{$R a=10^{8}$} & \multicolumn{2}{c|}{$R a=10^{7}$} & \multicolumn{3}{c|}{$R a=10^{6}$} & \multicolumn{2}{c|}{$R a=10^{5}$} \\
\hline & $N u_{i}$ & $N u_{o}$ & $N u_{i}$ & $N u_{o}$ & $N u_{i}$ & $N u_{o}$ & $N u_{i}$ & $N u_{o}$ \\
\hline Geometry 1 & 31.61 & 26.57 & 18.4 & 15.46 & 9.75 & 8.19 & 8.95 & 7.53 \\
\hline Geometry 2 & 27.78 & 26.35 & 16.17 & 15.34 & 8.95 & 8.49 & 8.32 & 7.89 \\
\hline Geometry 3 & 26.97 & 29.15 & 15.18 & 16.41 & 8.65 & 9.35 & 8.05 & 8.7 \\
\hline Geometry 4 & 26.13 & 28.25 & 14.98 & 16.19 & 8.74 & 9.45 & 8.05 & 8.7 \\
\hline Geometry 5 & 15.95 & 28.68 & 8.96 & 15.78 & 6.1 & 9.73 & 5.67 & 9.5 \\
\hline Geometry 6 & 15.34 & 28.54 & 8.57 & 15.85 & 5.35 & 9.91 & 5.23 & 9.68 \\
\hline Geometry 7 & 15.13 & 30.01 & 8.22 & 16.3 & 5.4 & 10.7 & 5.27 & 10.45 \\
\hline Geometry 8 & 14.62 & 29 & 8.08 & 16.04 & 5.44 & 10.8 & 5.27 & 10.45 \\
\hline
\end{tabular}

Another conclusion derived from Table (3) is that the 180-degrees rotation of triangular inner channel did not significantly affect the convection coefficient. There were slight variations found only at large Rayleigh numbers. This can be explained by the location of the triangle base (larger contact area) on the upper part of annular cylinders with greater heat transfer rate.

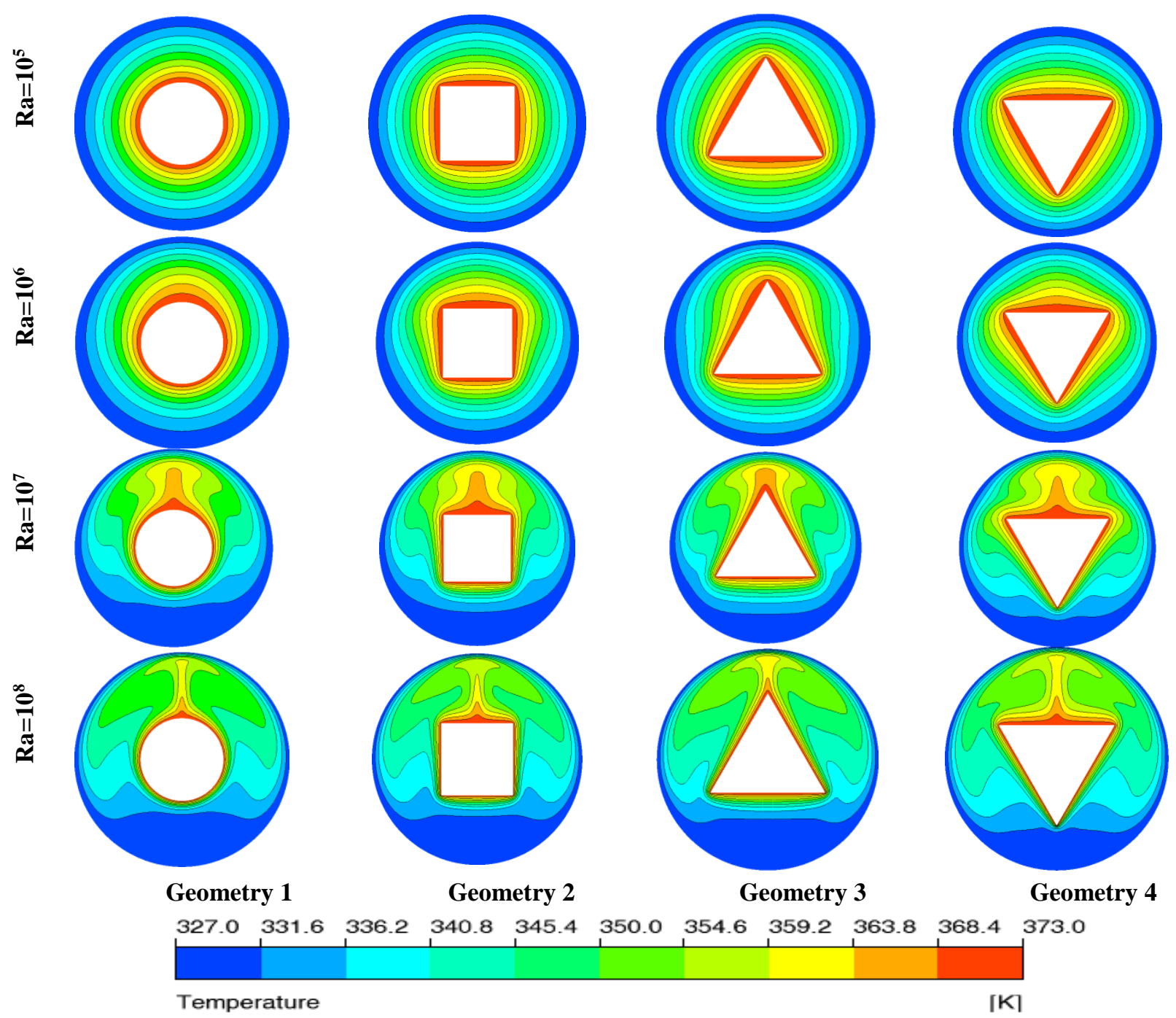

Fig. 5: Contours of fluid temperature at different Rayleigh numbers. 
Figure (6) illustrates the fluid temperature contour when fins have been included. The efficiency was employed based on thermal performance of fins. Efficiency is defined as the ratio of flux difference passing the inner channel surface of finned cylinder to non-finned cylinder based on the following equation [10].

$$
\varepsilon=\frac{q_{f i n}^{\prime \prime}-q_{\text {non }}^{\prime \prime}}{q_{\text {non }}^{\prime \prime}}
$$

As can be seen, the involvement of fins provided greater thermal efficiency for thermal circular channel than other channels. Furthermore, the performance of fins reduced at higher Rayleigh numbers (Figure (7).
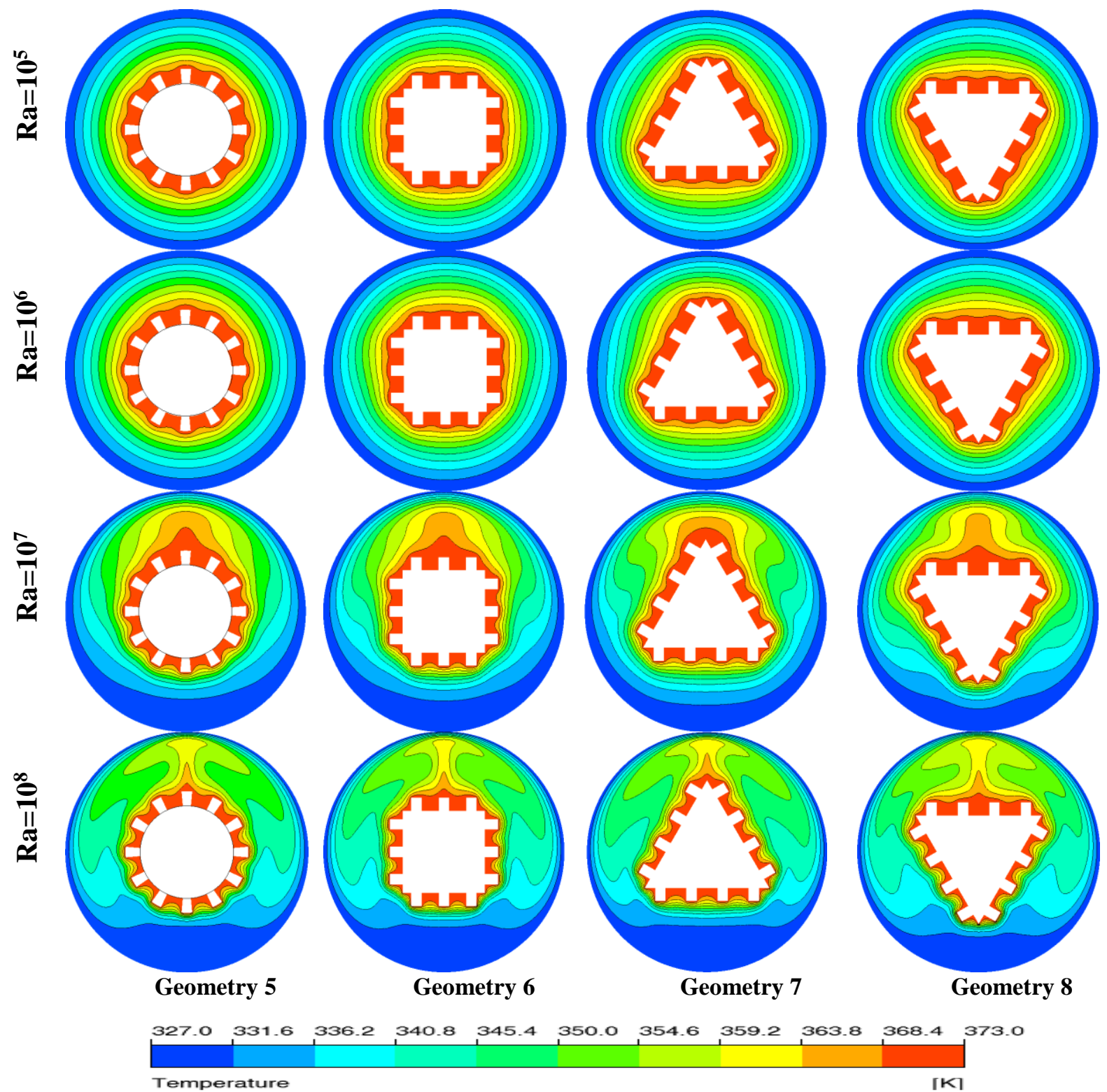

$350.0 \quad 354.6$

359.2363 .8

368.4

$[\mathrm{K}]$

Fig. 6: Contours of fluid temperature at different Rayleigh numbers in jagged fin cases. 


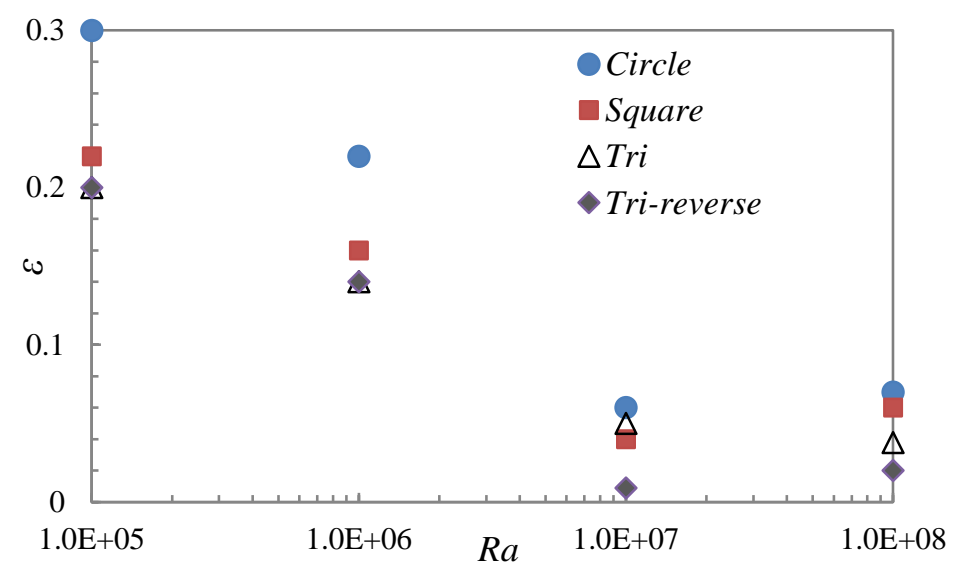

Fig. 7: Fin efficiency in increase of heat transfer rate.

\section{Conclusion}

This paper attempted to numerically examine the convection heat transfer of fluid water in the space between two channels and the effect of fins on inner channel surfaces. The outer channel of the annular cylinder was circular, while the outer channels involved three different cross-sections including circular, square and triangular with identical section areas. Moreover, the effect of fins on the inner surfaces of cylinders was tested by inserting identical square fins. The simulations were conducted at four Rayleigh numbers from $10^{5}$ to $10^{8}$. The results suggested that an increase in Rayleigh number led to greater convection heat transfer rate. It was also observed that involvement of fins inversely affected the heat transfer coefficient of the surface on which they have been mounted. That is because fins reduced the space of eddy currents caused by temperature differences and thus density variations. Although the convection heat transfer coefficient decreases, larger amount of heat is transferred from the inner surface of annular cylinders due to higher contact area created by fins. Since there is no heat source in annular cylinders, the heat exchanges in warm and cool surfaces are equal. And since the warm surface heat transfer intensifies, the cool surface heat transfer increases given the constant surface of the cool area. This trend is identical in all Rayleigh numbers and its intensity is directly correlated with the flow's Rayleigh number. Finally, the results demonstrated that the performance of fins is inversely correlated with the Rayleigh number, yielding maximum heat transfer for the circular channel.

$\begin{array}{cl}\text { Nomenclature } \\ G r & \text { Grashof number } \\ P r & \text { Prandtl number } \\ R a & \text { Rayleigh Number } \\ H T C & \text { Heat transfer coefficient } \\ \mathrm{Nu} & \text { Nusselt number } \\ \mathrm{K} & \text { Thermal conductivity } \\ \mathrm{L} & \text { length } \\ \mathrm{P} & \text { pressure } \\ T & \text { Temperature }\end{array}$

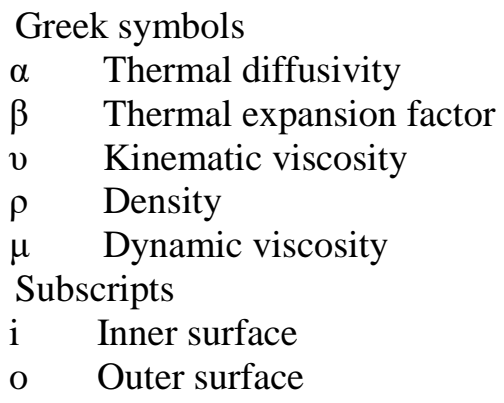

\section{References}

[1] T. H. Kuehn, R. J. Goldstein, "An Experimental Study of Natural Confection Heat Transfer in Concentric and Eccentric Horizontal Cylindrical Annuli," Journal of Heat Transfer, vol. 100, no. 4, pp. 635-640, 1978.

[2] T. H. Kuehn, R. J. Goldstein, "An experimental and theoretical study of natural convection in the annulus between horizontal concentric cylinders," Journal of Fluid Mechanic, vol. 74, no. 4, pp. 695-719, 1976.

[3] H. K. Dawood, H.A. Mohammed, N. Azwadi Che Sidik, K. M. Munisamy, M. A. Wahid, "Forced, natural and mixed-convection heat transfer and fluid flow in annulus: A review," International Communications in Heat and Mass Transfer, vol. 62, pp. 45-57, 2015. 
[4] R. Y. Sakr, N. S. Berbish, "Natural Convection Heat Transfer in a Horizontal Concentric Elliptic Annulus Containing Saturated Porous Media," Journal of Porous Media, vol. 15, no. 6, pp. 567-584, 2012.

[5] S. M. Seyyedi, M. Dayyan, S. Soleimani, E. Ghasemi, "Natural convection heat transfer under constant heat flux wall in a nanofluid filled annulus enclosure," Ain Shams Engineering Journal, vol. 6, pp. 267-280, 2015.

[6] M. Habibi Matin a, I. Pop, "Natural convection flow and heat transfer in an eccentric annulus filled by Copper nanofluid," International Journal of Heat and Mass Transfer, vol. 61, pp. 353-36, 2013.

[7] Ch. Zhang, L. Zheng, Y. Jiang, X, Zhang, "Unsteady natural convection heat transfer of nanofluid in an annulus with a sinusoidally heated source," Numerical Heat Transfer, Part A: Applications, vol. 69, no. 1, pp. 1-12, 2015.

[8] E. L. M. Padilla, R. Campregher, and A. Silveira-Neto, "Numerical Analysis of the Natural Convection in a Horizontal Annuli at Low and Moderate Ra," Thermal Engineering, vol. 5, no 02, pp. 58-65, 2006.

[9] J. C. Chai, S. V. Patankar, "Laminar Natural Convection in Internally Finned Horizontal Annuli," Numerical Heat Transfer, Part A: Applications, vol. 24, no. 1, pp. 6747, 1993.

[10] M. Arbaban, M. R. Salimpour, "Enhancement of laminar natural convective heat transfer in concentric annuli with radial fins using nanofluids," Heat Mass Transfer, vol. 51, no. 3, pp. 353-362, 2014. 